are recorded, and only claims to have shown this continuity as a consequence of known laws.

Prof. Van der Waals has been unfortunate in that the English dress in which his thesis appears is a translation from a translation. A literal rendering would have shown that he took his descriptions and diagrams from Maxwell's "Theory of Heat" because this is a "little book which is certainly in the hands of every physicist": it would have prevented the insertion of that footnote on p. 416 alluded to by Mr. Bottomley, since the text runs, "That Maxwell joins the points $\mathrm{C}$ and $\mathrm{G}$ by a straight line I do not think happy. It is apt to lead off the track and not on to it." The first of Mr. Bottomley's quotations-and with this, I might add, the scientific part of the preface of the original concludes-should read: " These considerations have led me to perceive continuity between the gaseous and liquid states, the existence of which, as I saw later, had been already surmised by others." Vermoed (surmised) certainly seems a weak word in the light of Dr. Andrews' experiments, but it may possibly point to an earlier date for Prof. Van der Waals's theoretical conclusion than that of his thesis.

Christ Church, Oxford. Robert E. Baynes.

\section{The Flying to Pieces of a Whirling Ring.}

DR. LODGE having set the ball of paradox rolling, perhaps I may be allowed to point out some of the paradoxes of his critics on the subject of revolving disks, of the well-known "grindstone problem." Prof. Ewing refers to two treatments of this problem, which, however, stand upon quite different footings. Prof. Grossmann's discussion reduces the problem to one in two-dimensions, and leaves an unequilibrated surface stress over both faces of the disk. Even if the disk be moderately thin, the solution cannot be considered satisfactory till the degree of approximation has been measured by comparison with the accurate solution of the problem. But Grossmann's method is precisely that of Hopkinson (Messenger of Mathematics, vol. ii., 1873, p. 53), except that the latter has dropped by mischance an $r$ in his equation (I) [or Grossmann's (6)]. This slip I pointed out in 1886 ; and Grossmann's results, such as they are, flow at once from Hopkinson's corrected equations. Between Hopkinson and Grossmann this theory has several times been reproduced in technical books and newspapers without comment on its want of correctness. Such first-class technical authorities as Ritter and Winkler have also given quite erroneous solutions of the "grindstone problem."

Prof. Boys refers to Clerk Maxwell's solution. Unfortunately the editor of his scientific papers has given no word of warning about the difficulties of that solution. It involves the paradox of an equilibrated shearing stress on the faces of the disk, and this stress is comparable with the stress which Maxwell supposes to burst the stone (see "History of Elasticity," vol. i. p. 827). Thus both the solutions suggested by Profs. Ewing and Boys suffer from the same defect of unequilibrated stress on the faces. Their difference leads to the fact that Maxwell's causes a hollow disk to burst first at the outer rim, and Grossmann's at the hole.

The solution by Mr. Chree, to which Prof. Ewing refers, seems to me to lie on a higher plane than the other two, and to have been better worth reproducing than Grossmann's, although it cannot be considered as final. $\mathrm{Mr}$. Chree recognizes that for his form of solution normal stresses over the faces of the disk would be necessary, and he proceeds to find their values. Grossmann failed to notice this paradox of his supposed solution, and therefore gives no measure of the amount of its error. Some years ago Mr. Chree kindly provided me for lecture purposes with a solution of the disk problem in which the stress on the disk face was zero over a circle of given radius. This was a closer approximation to the facts of the case, but as the stress was still unequilibrated at other points of the face the solution was not of course final.

If all these solutions are therefore paradoxical, where is the correct one to be sought? I fear it has yet to be worked out. Some progress can easily be made with it. It involves four series of Bessel's functions, two of either type, but the surface conditions lead to equations so complex that they will, I think, puzzle the ingenuity of our best Cambridge analysts. When solved, the work to be of practical value must be reduced to numerical tables and not left in the form of infinite series-a type of solution of elastic problem which is so common and yet so technically useless. An Italian has recently solved, by a finite number of definite integrals, the problem of the elastic spherical NO. I I I 7 , vOL. 43$]$ shell under given surface forces : possibly something might be done for the grindstone problem in the same direction. At any rate, my object in writing to NATURE is to point out that the solutions referred to by Profs. Ewing and Boys are incorrect, and to express a hope that no competent analytical elastician will, owing to these paradoxical solutions, hesitate to try his hand at a very important problem. I am quite certain that no real solution (the paradoxical are myriad) exists prior to 1860 , and pretty nearly certain that none has been achieved since, although my bibliography of papers on the strength of materials for the last twenty years is not so complete as I could wish.

University College, March 20.

Karl Pearson.

\section{Deductions from the Gaseous Theory of Solution.}

FrOM the gaseous theory of solution, Prof. Orme Masson has concluded (see NATURE of February 12, p. 345) that there must be some temperature above which two mutually soluble bodies will be infinitely soluble in each other. This, no doubt, is a fact, and it may be interesting to show that precisely the same conclusion can be drawn from the hydrate theory of solution.

Take first the case of a solution from which a solid separates on cooling. The body which separates, say solid water, does so owing to the tendency of its molecules to coalesce and form solid aggregates; and their tendency to do so is, we know, increased by lowering the temperature: on introducing any substance which possesses an attraction for the water molecules, the attraction of these for their fellows will be in part counterbalanced, and to get them to coalesce a lower temperature will be necessary, and the lower will this temperature be, the more foreign substance there is present; thus the freezing-point of the water will fall as the amount of, say, any salt present in it is increased, as in ADC, Fig. I. Similarly, if

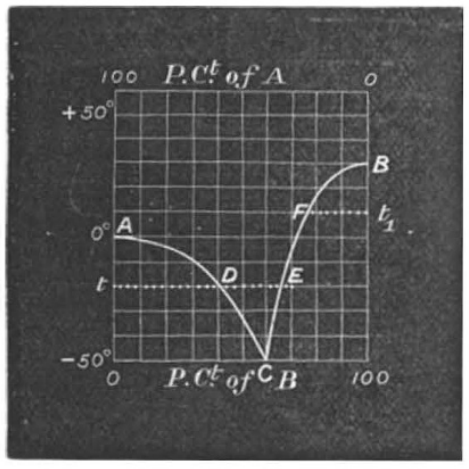

FIG. $x_{0}$

we start with the pure salt at $\mathrm{B}$, its freezing-point will be lowered by the addition of water, giving us a curve such as BFEC, which meets or cuts the first curve at some point $\mathrm{C}$ - the miscalled cryohydric point. This is precisely what does occur; the woodcut in fact represents the crystallization of water and the hexhydrate of calcium chloride from solutions of this salt, and may be taken as a typical example of the figures obtained in all cases. A solution of the composition $\mathrm{D}$ will be the one containing the most water of any which can exist at the temperature $t$, while $\mathrm{E}$ is the one containing the most salt at this temperature, all solutions of intermediate composition being capable of stable existence at $t$. At $t_{1}$ any solution weaker than $\mathrm{F}$ will be able to exist, since there is no inferior (i.e. for weak solutions) limit of stability, while above $\mathrm{B}$ there is neither superior nor inferior limit, and the two substances will be infinitely soluble in each other.

The same general results will obtain when the substances separate on cooling in the liquid instead of the solid condition, but they may be expressed in another form. From Fig. I we see that the maximum amount of $\mathrm{B}$ which the liquid $\mathrm{A}$ can hold at different temperatures is represented by $\mathrm{CB}$, and that this maximum increases with the temperature; it may be represented by AC, Fig. 2 ; similarly, the maximum amount of $\mathrm{A}$ which $\mathrm{B}$ can contain is represented by CA, Fig. I, or BC, Fig. 2, and we thus get in Fig. 2 a double curve which shows that at any tempera- 